\section{Tracheobronchial injury after rigid bronchoscopy - A rare but possibly catastrophic complication}

\author{
B. MATIAS ${ }^{[1]}$, P. CONDE ${ }^{[2]}$
}

[1] - Department of Anaesthesiology, Centro Hospitalar de Setúbal, EPE - Portugal
CENTRO HOSPITALAR LISBOA NORTE, EPE

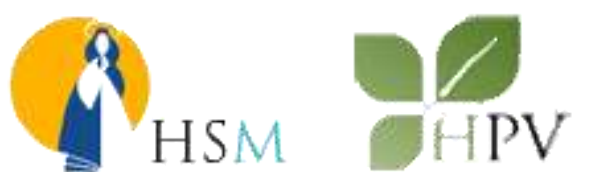

Centro Hospitalar de Setúbal Hospital de São Bernardo

Hospital Ortopédico Sant'lago do Outão

\section{BACKGROUND}

Tracheobronchial injuries are rare but potentially lifethreatening complications of endotracheal intubations or endobronchial interventions. Surgical repair is the classic treatment, but conservative management in selected cases has recently been reported ${ }^{1}$.

\section{CASE REPORT}

61-year-old woman, proposed for rigid bronchoscopy after a three-month history of progressive dyspnea and dysphagia, with occasional episodes of stridor. Cervicothoracic CT scan revealed middle esophageal mass with tracheal infiltration. Procedure performed under general anesthesia and airway managed with highfrequency jet ventilation. Tracheal mass resection was uneventful but carinal stent placement proved difficult, with multiple traumatic attempts needed before final positioning. Recovery from anesthesia took place without any immediate complications.

Three hours after the procedure, the patient developed sudden dyspnea and rapidly progressing subcutaneous emphysema. Emergent rigid bronchoscopy was performed (same anesthetic management), during which a carinal tear was found. A new stent was placed and endotracheal tube inserted inside the stent, with fiberscope guidance. Mechanical ventilation was possible with minimal leakage and emphysema progression stopped. Chest $\mathrm{x}$-ray revealed exuberant pneumomediastinum and pneumoperitoneum, confirmed through thoracic and abdomino-pelvic CT scan. Conservative management was decided and patient admitted to Intensive Care Unit.

Two weeks after the intervention another bronchoscopy revealed healing. However, it also revealed rapid local infiltration of the neoplastic mass (histology identified a squamous cell carcinoma), with left bronchus obstruction and progressive hypoxemia, which lead to patient death three weeks after the initial event.
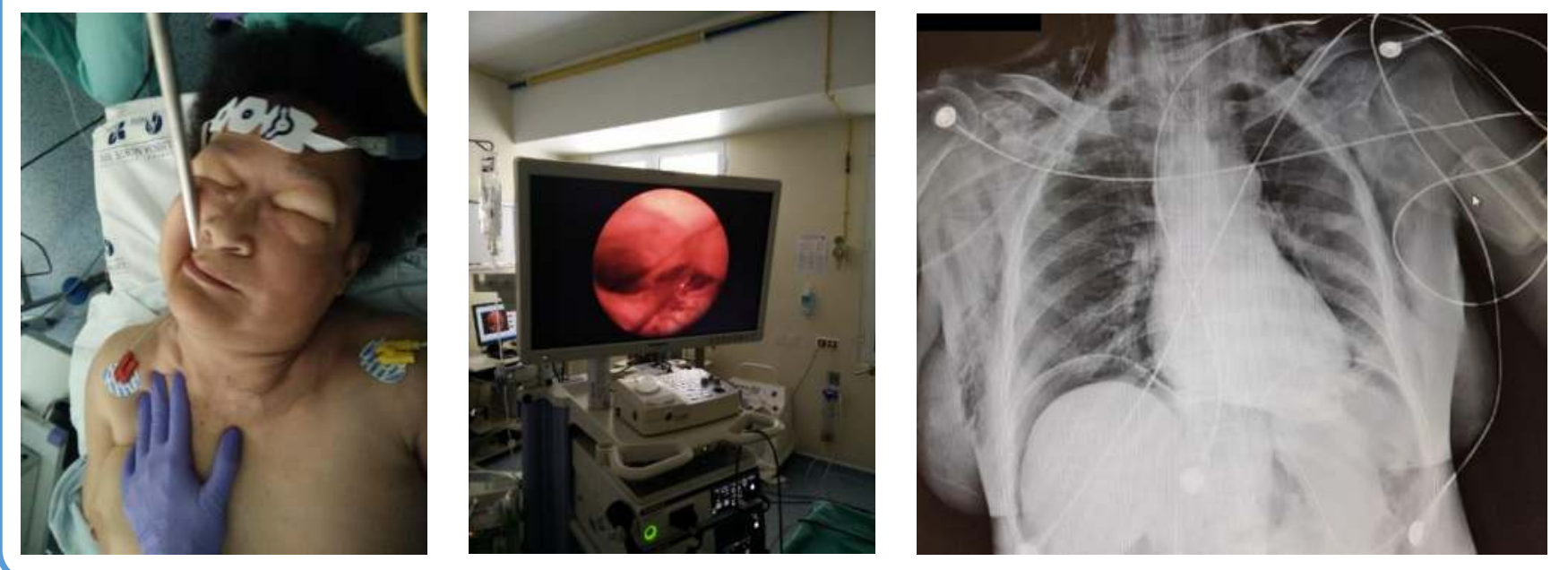

\section{DISCUSSION}

latrogenic tracheobronchial injuries are rare complications and endobronchial endoscopy/ intervention accounts for only about $10 \%$ of lesions ${ }^{1}$. Subcutaneous emphysema is the most common finding ${ }^{2}$. Although clinical signs occurred immediately or shortly after extubation, the time interval between injury and diagnosis can go up to 5 days ${ }^{3}$. Tracheobronchoscopy is the gold standard for diagnosis, prognosis and planning treatment ${ }^{3}$.

Consensus on treatment, which can be conservative or surgical, has not been reached yet, and depends on the clinical presentation and overall condition of the patient, and the etiology, location and size of the lesion ${ }^{3}$. Conservative treatment can include the application of fibrin sealant onto the lesion ${ }^{3}$ or the placement of a stent, only licensed for malignant conditions $^{4}$. Currently the rate of conservative treatment in series of patients ranges from $33,3 \%$ to $94,4 \%^{2}$. Strict follow-up is necessary and surgery should be undertaken once airway loss, inadequate ventilation or infection/sepsis occurs².

In our case, nonoperative conservative management was chosen and was a safe option for initial management. Our result is in agreement with others already published ${ }^{1}$, regardless of the outcome, as prognosis is mostly related to the underlying disease rather than the tracheal injury ${ }^{3}$, and emphasizes the importance of early diagnosis and intervention.

\section{LEARNING POINTS}

Tracheobronchial injuries are rare but potentially lifethreatening complications of endotracheal intubations or endobronchial interventions. Conservative management is possible in selected cases.

\section{REFERENCES}

\section{1-Ann Thorac Surg 2007; 83:1960-4}

2-Journal of Cardiothoracic Surgery 2014; 9:117

3-Open Journal of Thoracic Surgery 2013; 3:130-134

4-British Journal of Anaesthesia 2003; 90(3):367-74

Euroanaesthesia

GENEVA 03-05 JUNE

THE EUROPEAN ANAESTHESIOLOGY CONGRESS 